FINANCIAL ENGINEERING 


\title{
Financial Engineering
}

\author{
BRIAN A. EALES
}

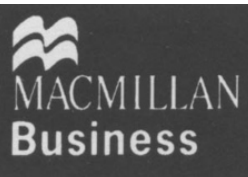




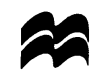

(C) Brian Eales 2000

All rights reserved. No reproduction, copy or transmission of this publication may be made without written permission.

No paragraph of this publication may be reproduced, copied or transmitted save with written permission or in accordance with the provisions of the Copyright, Designs and Patents Act 1988, or under the terms of any licence permitting limited copying issued by the Copyright Licensing Agency, 90 Tottenham Court Road, London W1P 9HE.

Any person who does any unauthorised act in relation to this publication may be liable to criminal prosecution and civil claims for damages.

The author has asserted his right to be identified as the author of this work in accordance with the Copyright, Designs and Patents Act 1988.

First published 2000 by MACMILLAN PRESS LTD

Houndmills, Basingstoke, Hampshire RG21 6XS and London

Companies and representatives

throughout the world

ISBN 978-0-333-73785-9

ISBN 978-1-349-27856-5 (eBook)

DOI 10.1007/978-1-349-27856-5

A catalogue record for this book is available from the British Library.

$\begin{array}{llllllllll}10 & 9 & 8 & 7 & 6 & 5 & 4 & 3 & 2 & 1\end{array}$

$\begin{array}{llllllllll}09 & 08 & 07 & 06 & 05 & 04 & 03 & 02 & 01 & 00\end{array}$ 


\section{Contents}

Preface

Acknowledgements

vii

1 Introduction 1

2 The Building Blocks: Exchanged-Based Contracts 31

3 Forward Rate Agreements and Interest Rate Swaps 78

4 Forward Exchange Rates and Currency Swaps 104

5 Equity Swaps 121

6 Regular and Exotic Options 140

7 Alternative Pricing Approaches $\quad 178$

$\begin{array}{llr}8 & \text { Fixed Income Securities } & 197\end{array}$

9 Convertible Bonds $\quad 221$

$\begin{array}{lll}10 & \text { Applications } & 245\end{array}$

$\begin{array}{lr}\text { Notes } & 285\end{array}$

$\begin{array}{ll}\text { Index } & 287\end{array}$ 


\section{Preface}

This text provides a practical insight into the ways in which forwards, futures, options and swaps can be combined and/or modified to create financial products that deliver pre-defined payoffs on a single future date or at intervals over a period of time. The operational characteristics of the instruments are discussed in an applied context with examples drawn from equity, interest rate, and currency markets.

There are a number of audiences who will find this book useful:

Advanced undergraduates following programmes in business, economic or finance and accounting. Graduate students on MSc, MBA, and MA and programmes where financial markets and instruments receive attention. Practitioners who want to develop a deeper understanding of how the instruments work in practice, their limitations and their uses in developing special financial products.

A suite of Excel Version 5 (and Excel Office 97) semi-automated spreadsheets, to run on an IBM or IBM compatible PC, are supplied with the text. The spreadsheets, which assume some background computer knowledge on the part of the user, will allow the user to experiment with different types of instruments and run 'what if' simulations based on his or her own projected scenarios, using up-to-date data drawn from the financial pages of the press. In addition many examples using control data are illustrated and discussed in the text.

It must be emphasised that the spreadsheets are to be regarded as teaching/learning tools. They provide a vehicle for examining examples of pricing and engineering outcomes that would prove tedious and time consuming, or even impossible, using a standard hand calculator especially where dates or day counts are involved or the area under a normal curve is to be calculated. There are, of course, simplifications that have been made in order to avoid making the spreadsheets overly complex, for example, dividend receipts have been ignored in portfolios of equity, transactions costs are also conveniently omitted as are costs associated with the running of a margin account. The spreadsheets have been constructed to be as transparent and accessible as possible and, in many cases, can be modified easily to allow even more 'real-world' scenarios to be examined by the user.

Each chapter contains descriptions of the instrument being used and, where appropriate, how it is priced together with an outline of the methodology which underpins its derivation. The chapters can also be used in conjunction with spreadsheets which provide an insight into a topic and, in most cases, allow users to simulate the control or their own outcomes. A list of the spreadsheets accompanying each chapter along with a brief description of their function is included as the last section of each chapter. Where appropriate, end of chapter questions are also supplied, some of which require the collection of data as input to the spreadsheets. The intention here is that classes will be able to analyse and 
discuss a variety of outcomes based on different projections of future market movements without the need to undertake manual, tedious computations.

Financial engineering is a subject of growing interest and importance in many spheres of financial and business activity, and for some courses teaching the whole of the book would be a desirable and appropriate course of action. However, in writing a text which gives in-depth coverage to the major financial instruments, it is inevitable that parts of it will be of little interest to some readers. With this in mind a structure has been used which provides essential, general background in the early chapters, but allows a good degree of specialisation in later chapters.

Chapter 1 introduces the subject and discusses some of the basic risk and return measurement statistics encountered throughout modern finance. Chapter 2 provides an intuitive insight into financial engineering with examples drawn from the equity and short-term interest rate arenas. Chapters 3, 4 and 5 introduce and develop the background and mechanics of interest rate, currency and equity swaps. Chapters 6 and 7 cover the use and pricing of regular exchange-based and exotic options. In the context of pricing several frameworks are introduced and are employed in Chapters 8 and 9 in the context of Option Adjusted Spread Analysis, and the pricing of convertible bonds. In the final chapter the tools and instruments discussed and developed in earlier chapters are brought together to analyse several financial product structures. The aim of this chapter is to examine how engineered products can be broken down into component parts to identify how the product has been priced and provide an indication of how risk hedging may be facilitated.

Structuring the text into separate sections in this way enables the reader to come to grips with the salient features of basic financial instruments that can be combined to form more complex strikers that meet an end-user's requirements. Moreover, once the strengths and limitations of the construction elements are understood the process of building complex or hybrid products becomes more transparent, and with that transparency risk exposure becomes easier to identify and hedge as necessary from each counterparty's perspective.

While the jargon used by market professionals to describe their instruments varies between markets, the fundamental application of those instruments remains the same. Indeed, the instruments described in this text are also available in commodity markets, which implies that the strategies discussed here in the context of paperbased securities, with some adjustments, could equally well be applied to those arenas dealing in physical commodities.

\section{CURRENCY AND EXCHANGE RATES}

Although some of the examples involving foreign exchange in this text are presented in terms of Deutschemarks, French francs, and other pre-Euro currencies, the methods discussed for pricing derivatives are equally applicable to the Euro. Should the Euro survive its current slide against the US dollar and the early pressures under which it has been placed - and the evidence suggests that the eleven participants 
in its introduction are determined from both a political and an economic viewpoint that it will - the familiar labels of DM, franc, lira will disappear. Currency risk will then be looked at in terms of USD/Euro, Yen/Euro, etc, and, of course, should the UK fail to join its EU partners in the European Monetary Union common currency venture, GBP/Euro exchange rate risk will also exist.

The Euro came into existence at Central European Time 00:00 on 1 January 1999 when eleven countries fixed their domestic currency exchange rate against the Euro. The following table presents the amount of each domestic currency required to convert to one Euro:

\begin{tabular}{lll}
\hline Country & \multicolumn{1}{c}{ Euro } & Rate \\
\hline Austria & Austrian Schillings & 13.7603 \\
Belgium & Belgian Francs & 40.3399 \\
Finland & Finish Marks & 5.94573 \\
France & French Francs & 6.55957 \\
Germany & Deutschemarks & 1.95583 \\
Ireland & Irish Punt & 0.787564 \\
Italy & Italian Lira & 1936.27 \\
Luxembourg & Luxembourg Francs & 40.3399 \\
Netherlands & Dutch Guilder & 2.20371 \\
Portugal & Portuguese Pesetas & 200.482 \\
Spain & Spanish Pesetas & 166.386 \\
\hline
\end{tabular}

\section{COMPUTER BACKGROUND}

The text assumes that students will have some familiarity with spreadsheets, and will have some basic knowledge of MS-DOS, for example, how to copy files across disk drives and set up a default directory. University students will normally have completed a one-term introductory computing/information technology course.

All the spreadsheets have been written for Excel Version 5 (some Excel Office 97) to run on an IBM or an IBM compatible PC. The spreadsheets can be run on a stand-alone machine or on a PC network. Each spreadsheet has been tested on London Guildhall University's network by several cohorts of students on the MSc Financial Markets and Derivatives and BA Financial Economics degrees. The spreadsheets may be run from either floppy or hard disk drive. Before using the disk containing the spreadsheets for the first time, the user is advised to make a back-up copy of the original. The easiest way in which to ensure that the spreadsheets and databases are all readily accessible on the stand-alone PC is to make the directory housing the files accompanying this text the default directory. 


\section{Acknowledgements}

In writing this book I am indebted to a number of colleagues, students and other sources for their support and encouragement: The influence of several colleagues within the University and in the City of London provided me with the inspiration to write abook on financial engineering; in particular Kevin Connolly, Geoffrey Hilliard, Andrew Wood, Jerry Coakley, Joe Pearlman, and Kostas Giannopoulos, who have either read drafts of chapters and/or made useful suggestions on content, level, presentational style and construction of some of the material covered. Their constructive criticisms have proved invaluable; any errors or omissions rest with me.

Students on the university's MSc Financial Markets \& Derivatives degree; MBA, Financial Risk Management unit, and third year BA Financial Economics courses, have all contributed to the development and reliability of the spreadsheets, as well as working through most of the questions at the end of chapters. Without the students' participation the spreadsheets presented in the text would have had no proving ground.

Sam Whittaker at Macmillan proved a valuable source of encouragement and assistance throughout the venture. The anonymous reviewer's comments were also of great help, greatly appreciated and, I hope have led to an improvement in the text's layout and coverage.

I should also like to thank the London International Financial Futures and Options Exchange (LIFFE) ${ }^{1}$ for allowing me to quote its contracts in the text, and use them to illustrate many of the examples of hedging, and Futures and over the Counter World for supplying me with their templates for the world's major exchange-based contracts for use in the text.

Finally I should like to thank my wife, to whom this book is dedicated, and children for so patiently putting up with the disruption to family life caused by this undertaking.

1 Neither LIFFE nor its servants and agents is responsible for any errors or omissions contained in this booklet (material), which is published for information purposes and shall not constitute investment advice. All descriptions, examples and calculations contained in this booklet (material) are for guidance purposes only and should not be treated as definitive. Whilst all reasonable care has been taken to ensure that the details are true and not misleading at the time of publication, no liability is accepted by LIFFE for use of information contained herein in any circumstances connected with actual trading or otherwise. LIFFE reserves the right to alter any of its rules or contract specifications, and such an event may affect the validity of the information contained in this booklet (material). 